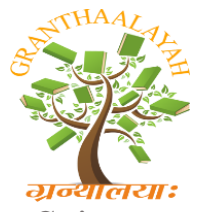

Science

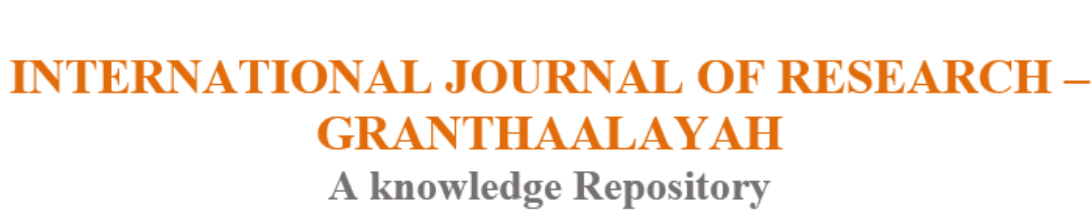

A knowledge Repository

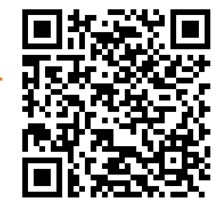

\title{
IMMUNOHISTOCHEMICAL EXPRESSION OF LATENT MEMBRANE PROTEIN- 1 (LMP-1) AMONG SUDANESE PATIENTS WITH NASOPHARYNGEAL CARCINOMA
}

\author{
Ibrahim Bakhit Yousif Elemam ${ }^{1}$, Yousif Mohammed Yousif², \\ Mohammed Sideeg Abd Elaziz ${ }^{3}$ \\ ${ }^{1}$ Department of Histopathology and Cytology -Faculty of Medical Laboratory Sciences -Shendi \\ University- SUDAN \\ ${ }^{2}$ Department of Otorhino Laryngology Faculty of Medicine -Shendi University- SUDAN \\ ${ }^{3}$ Department of Histopathology and Cytology-Faculty of Medical Laboratory Sciences -Sudan \\ University for Sciences and Technology- SUDAN
}

\begin{abstract}
Nasopharyngeal carcinoma (NPC) has a unique and complex etiology that is not completely understood. The distinctive racial/ethnic and geographic distribution of NPC worldwide suggests that both environmental factors and genetic traits contribute to its development. The aims of this study was to investigate the association of LMP-1 EBV in theses tumors in Sudan To assess the expression pattern of LMP-1 immunohistochemical stain in the different histological types of NPC and to define any association between the expression of LMP-1 with the sex, the age and the histological types of NPC.

Archival formalin-fixed, paraffin-embedded NPC biopsies were evaluated in 35 biopsies for the presence of LMP1 using immunohistochemistry (IHC).

Histologically the cases were, (54\%) (19/35) of squamous cell carcinomas subtypes, (26\%) (9/35) of undifferentiated squamous cell carcinoma and (20\%) (7/35) of keratinized squamous cell carcinomas. LAMP-1 detected in five (5/9) (55\%) of undifferentiated squamous cell carcinoma, positive, four (4/19) (21\%) of non keratinized squamous cell carcinoma and in two (28\%) (2/7) of keratinized squamous cell carcinoma, with (P.value $=0.182)$, so there is no statistically significant different in the correlation of $\mathrm{EBV}$ with histological subtypes of nasopharyngeal carcinoma.

This study confirms that EBV is present in a subset of Sudanese NPC patients. Our results are consistent with those reported by other studies concerning the same NPC endemic risk area and provide original data concerning Sudan.
\end{abstract}

Keywords:

Epstein-Barr virus, Immunohistochemistry, LMP1, Nasopharyngeal carcinoma.

Cite This Article: Ibrahim Bakhit Yousif Elemam, Yousif Mohammed Yousif, and Mohammed Sideeg Abd Elaziz, "IMMUNOHISTOCHEMICAL EXPRESSION OF LATENT MEMBRANE PROTEIN- 1 (LMP-1) AMONG SUDANESE PATIENTS WITH NASOPHARYNGEAL CARCINOMA" International Journal of Research - Granthaalayah, Vol. 3, No. 9(2015): 101-107. 


\section{INTRODUCTION}

Nasopharyngeal carcinoma (NPC) is a malignant epithelial neoplasm with a remarkable geographic and racial distribution worldwide. Indeed, globally, there are three distinct endemic areas: an area with very high frequency in southern China (Canton), where the incidence is 30 to $80 / 100000$ / year. $\stackrel{1,2}{2}$ An area of intermediate frequency (8 to $12 / 100$ 000/year) in Taiwan, Vietnam, Thailand, Malaysia, the Philippines, the Caribbean, the Mediterranean (Maghreb and Middle East), Alaska and Greenland ${ }^{3}$, and finally an area of low frequency in North China, Europe and the United States (0.5 to $2 / 100$ 000/year). $\frac{4,5}{2}$

The WHO classifies NPC into three histologic types: keratinizing squamous cell carcinoma (type I); and nonkeratinizing carcinoma, characterized as differentiated (type II) or undifferentiated (type III; ref. ${ }^{7}$. Type III NPC comprises over $95 \%$ of NPC in high-incidence areas, and most of the remaining $5 \%$ is type II NPC $\stackrel{9,12}{2}$; in contrast, type I NPC is predominant in low-incidence regions, and may have an etiology distinct from that of the other two histologic types $\underline{13}$. Although NPC is a rare malignancy throughout most of the world $\frac{1}{}$, it is endemic in a few well-defined populations. In 2002, 80,000 incident cases of nasopharyngeal cancer were diagnosed worldwide and the estimated number of deaths exceeded 50,000, making it the 23rd most common new cancer in the world 11 ; in contrast, NPC was the fourth most common new malignancy in Hong Kong $\underline{10}$. Arising in the epithelial lining of the nasopharynx, NPC comprises the vast majority of nasopharyngeal cancers in both high- and low-incidence populations $\underline{8,6}$.

NPC forms around 6\% of all cancer cases in the Sudan Cancer Registry (SCR) records, and 7\% at the Radiation Isotope Center-Khartoum (RICK). Although Sudan is categorized as an intermediate risk country, there have been only two reports since $1983 . \underline{14,15}$

The etiology of NPC is multifactorial and currently available data suggest a complex interplay of genetic, viral, environmental and dietary factors. Indeed, various human leukocyte antigens (HLA), such as HLA-A2, HLA-B17 and HLA-Bw46, are important etiologic or prognostic indicators in NPC. ${ }^{16}$ As well, Epstein-Barr virus (EBV) is consistently detected in patients with nasopharyngeal carcinoma ${ }^{17,18}$, suggesting a role in the NPC pathogenesis. In intermediate to high risk Chinese populations, consumption of salted fish, especially during weaning in childhood, is associated with elevated risk of NPC $\stackrel{19}{ }$. The carcinogenic potential of salt-preserved food can be explained by the accumulation of significant levels of nitrosamines, which are known for their carcinogenic properties $\underline{20}$. Salt-preserved fish also contain bacterial mutagens, direct genotoxins, and EBV-reacting substances, any or all of which could also contribute to the NPC risk $\underline{20}$.

\section{MATERIAL AND METHODS}

This prospective study, was carried out in the Radio Isotope Center Khartoum (RICK)-Khartoum State -Sudan, in the period from January 2014 to July 2015, the geographical and histoclinical data were achieved from the patients files , and Formalin -fixed paraffin embedded biopsies of (35) of Nasopharyngeal carcinoma, samples were used to investigate the positive rate of EBV, by anti (LMP-1) Immunostain according to standard Strepto Avididin Biotin (Thermo Fisher) protocol. The data was analyzed, using the statistical programs software Statistical Package for the 
Social Sciences (SPSS) version (11.5), Chi square test and different statistical measures were calculated.

The Immunochistochemical procedure was done as follows: Three microns $(3 \mu \mathrm{m})$ sections from formalin-fixed, paraffin-embedded were cut and mounted onto salinized slides (Fisher brand). Monoclonal antibody (LMP-1) was used as manufacture instructions to detect presence of $(E B V)$ from both case and control samples. All sections were deparaffinized in two changes of xylene for 10 minutes in each change, then rehydrated in descending changes of ethanol as follows; sections were placed in two changes of absolute ethanol for 5 minutes in each change and then were placed in $90 \%$ ethanol for 3 minutes, and then were placed in $70 \%$ ethanol for 2 minutes, and then were washed in distilled water for 2 minutes. Sections were steamed for antigen retrieval for $(E B V)$ using (PT link) in 10mM- citrate buffer Hydrochloric acid $(\mathrm{HCl})(\mathrm{pH} \mathrm{7.6)}$ for 20 minutes. Then slides were cooled in a sink containing cold tap water, the slides were removed once the buffer at room temperature, slides were rinsed in running tap water and placed in TBS at pH 7.4. Endogenous peroxidase activity was blocked with $3 \%$ hydrogen peroxide in methanol for 10 min, then ultra V block was applied and incubated for 8 min and then Slides were incubated with 100 $\mu l$ of primary antibodies for $20 \mathrm{~min}$ at room temperature in a moisture chamber, and then were rinsed in Phosphate buffer saline. The primary antibody for EBV (Monoclonal antibody (LMP-1) was ready to use (Thermo Fisher). After washing with PBS for 3 minutes, binding of antibodies was detected by incubating with biotinylated goat anti polyvalent for 15 minutes, followed by incubating for 15 min with streptavidin peroxidase (Thermo Fisher kit). the slides then were be washed with two rinses of TBS $\mathrm{pH} 7.4$ for 1-2 minutes followed, then the slides were be covered by $0.01 \% \mathrm{H}_{2} \mathrm{O}_{2}$ and 0.053 .3 diamino benzidine tetra hydro chloride (DAB) chromogen in Tris $\mathrm{HCl} \mathrm{pH} 7.6$ for 5 minutes at room temperature, (Thermo Fisher) as a chromogen to produce the characteristic brown stain for the visualization of the antibody/enzyme complex. the sections was counter stained with Mayer's Haematoxylin for one minute, washed in tap water for 2 minutes, dehydrated through 3 different baths of absolute alcohol, placed in xylene, mounted in (DPX). For each run of staining, positive and negative control slides was also prepared. The positive control slides contain the antigen under investigation and the negative control slides prepared from the same tissue block, but were incubated with PBS instead of the primary antibody. Each slide was evaluated with investigator then the results were confirmed by consultant histopathologist.

\section{RESULT}

The study group comprised Formalin -fixed paraffin embedded Nasopharyngeal carcinoma biopsies of thirty five (35), all cases were selected from the surgical pathology obtained from the archives of Radiation Isotope Center Khartoum $(R I C K)$ after taking the numbers of blocks from the patient records data of the following years (2011, 2012, 2013 and 2014). Clinical and pathological aspects such as age, sex and histological types were abstracted from reports and clinical records, all the histological samples were confirmed, by histopathologist.

In this study the frequency of nasopharyngeal carcinomas among males and females were $(71.4 \%)$ $(25 / 35)$ and $(28.6 \%)(10 / 35)$ respectively, the male: female ratio was 2.5:1 (Table.1)

Regarding the frequency of nasopharyngeal carcinomas among different age groups, It was more frequent in the middle age, fourteen cases (14/35) (40\%) and fourteen cases (14/35) (40\%) in 
elderly and less frequent in children and young adults, it was seven cases (7/35 - 20\%) as in Table 2.

Considering the histological subtypes of nasopharyngeal carcinomas, the highest frequency was non keratinized Squamous Cell Carcinomas subtypes (54\%) (19/35) followed by Undifferentiated Squamous Cell Carcinoma (26\%) (9/35), then keratinized Squamous Cell Carcinomas (20\%) (7/35), as shown in (Table.3)

The correlations between LMP-1 expression and the three histological forms of nasopharyngeal carcinomas histological types, are summarized in (Table.4), LAMP-1 detected in five (5/9) (55\%) of undifferentiated squamous cell carcinoma, positive, four (4/19) (21\%) of non keratinized squamous cell carcinoma and in two (28\%) (2/7) of keratinized squamous cell carcinoma, with (P.value $=0.182)$, so there is no statistically significant different in the correlation of EBV with histological subtypes of nasopharyngeal carcinoma.

Table 1: Distribution of study population according to the gender

\begin{tabular}{|l|l|l|}
\hline Gender & Frequency & Present \\
\hline Male & 25 & 71.4 \\
\hline Female & 10 & 28.6 \\
\hline Total & 59 & 100 \\
\hline
\end{tabular}

Table 2: Distribution of study population according to the age

\begin{tabular}{|l|l|l|}
\hline Age & Frequency & Present \\
\hline Less than 30yrs & 7 & 20 \\
\hline 30 to 50 yrs & 14 & 40 \\
\hline More than 50 yrs & 14 & 40 \\
\hline
\end{tabular}

Table 3: The frequency of Nasopharyngeal Carcinoma subtypes

\begin{tabular}{|l|l|l|}
\hline NPC subtype & Frequency & Present \\
\hline Non K S. C. C & 19 & 54.3 \\
\hline K S. C. C & 7 & 20.0 \\
\hline Undifferentiated S.C.C & 9 & 25.7 \\
\hline Total & 35 & 100 \\
\hline
\end{tabular}

Table 4: EBV IHC, comparison between different histological types of NP

\begin{tabular}{|l|l|l|l|l|}
\hline \multirow{2}{*}{ Diagnosis } & \multicolumn{2}{|l|}{ IHC } & Total & \multirow{2}{*}{ P.value } \\
\cline { 2 - 4 } & \multicolumn{2}{|l|}{ +ve } & \multicolumn{3}{l|}{-ve } & & \\
\hline Non K S. C. C & 4 & 15 & 19 & \\
\hline K S. C. C & 2 & 5 & 7 & \multirow{2}{*}{0.182} \\
\hline Undifferentiated S.C.C & 5 & 4 & 9 & \\
\hline
\end{tabular}




\begin{tabular}{|l|l|l|l|l|}
\hline Total & 11 & 24 & 35 & \\
\hline
\end{tabular}

\section{DISCUSSION}

The study also investigates the nasopharyngeal carcinoma and its association with EBV infection. NPC forms around 6\% of all cancer cases in the Sudan Cancer Registry (SCR) records, and (7\%) at the Radiation Isotope Center Khartoum (RICK).Sudan is categorized as an intermediate risk country. $\underline{21}$

Our data may not reflect the situation in the general population, especially as we worked on a sizereduced series (35 cases), but our results are in keeping with those previously reported. In fact, we found that males were more affected by nasopharyngeal cancer than females ((71\% versus $29 \%$ respectively) with a sex ratio of (2.5). These findings were in agreement with a previous Sudanese published study by Ameera, et al, their results showed that; "in the gender frequency of patients with NPC, $(79.1 \%$ males versus $20.9 \%$ female). $\underline{22}$ Such a male predominance in the incidence of NPC may be partly explained by differences between the sexes in the prevalence of some environmental risk factors, such as smoking and hazardous occupational exposures. It is also possible that some intrinsic exposures, such as sex hormones, could account for the observed male predominance by a protective effect of endogenous estrogen, this explanations supported by Xie, et al, their conclusions ( The age-dependent pattern of the sex difference in the incidence of NPC could not be completely explained by known risk factors for NPC. The contributions of intrinsic exposures, such as sex hormones, merit consideration. $\underline{23}$

In this study most patients with NPC were in middle age and elderly, these findings were in line with study conducted in Indonesia by Adham, et al, in this study population, NPC was the most frequent Head and neck cancer (28.4\%), with a male-to-female ratio of 2.4, and NPC appeared to affect patients at a relatively young age. $\underline{24}$

As considering the histological subtypes of NPC ,the study emphasized the predominance of non keratinized squamous cell carcinomas (54\%) followed by undifferentiated squamous cell carcinoma (26\%), then keratinized squamous cell carcinomas(20\%), this result resembles that of endemic areas, with a predominance of Types II and III which associated with high rates of EBV detection.$\underline{25}$

As regard to histological subtypes of NPC ,the LMP-1 was detected in ( $55 \%, 28 \%, 21 \%)$ of cases of undifferentiated squamous cell carcinoma, keratinized squamous cell carcinoma and in Non keratinized squamous cell carcinoma respectively without statistically signinificant differences considering the association between EBV and the histological subtypes, the (P.value $=0.182$, ), so the undifferentiated squamous subtypes have the highest positive rate. These findings agreement with the study conducted in Sudan by Ameera, et al, their findings (the undifferentiated form record (100\% EBV positive which detected by EBER-ISH). ${ }^{22}$ the study data were also supported by findings of (Vera et al 1998), as their conclusions showed (76.36\%) of NPC cases positive nuclear signals were observed using EBV-ISH. Overall, EBV-ISH positivity varied according to histological type, in that undifferentiated carcinomas showed higher proportion of positive cases than differentiated cell carcinoma. $\underline{26}$ 
Other study by Hording, et al, confirmed the association of undifferentiated squamous cell carcinoma subtype of NPC and EBV infection (100\%), but less frequent one with keratinizing NPC (14\%) The results may indicate a different carcinogenesis for the WHO 1 NPC subtype. $\underline{27}$

\section{CONCLUSION}

Our study concluded that the LMP-1 was detected in all cases of NPC subtypes without statistically significant differences considering the association between EBV and the histological subtypes, which consistent with those reported by other studies concerning the same NPC endemic risk.

\section{ACKNOWLEDGMENTS}

I would like to thank the work team of Radiation Isotope Center Khartoum (RICK), especially Nada Saleh, also my deep thanks extended to staff of Faculty of Medical Laboratory SciencesShendi University.

\section{REFERENCES}

[1] Yu MC, Yuan JM. Epidemiology of nasopharyngeal carcinoma. Semin Cancer Biol. 2002;12:421-429. [PubMed[

[2] Stewart BW, Kleihues P. World Cancer Report chap. Head and neck cancer. Lyon: IARC Press; 2003. p. 322.

[3] Seigneurin JM, Fafi-Kremer S, Baccard M, Morand P. Cahier de formation biologie médicale: Le virus Epstein-Barr et les marqueurs de l'infection. 36 2006. (Fre.(

[4] Brennan B. Nasopharyngeal carcinoma. OJRD. 2006;1:23. [PMC free article] [PubMed[

[5] Busson P, Ooka T, Corbex M. Carcinomes nasopharyngés associés au virus d'EpsteinBarr : De l'épidémiologie à la thérapeutique et au dépistage. médecine sciences. 2004;20(4):453-457. (Fre). M/S. [PubMed]

[6] Parkin DM, Whelan SL, Ferlay J, Teppo L, Thomas DB, editors. Cancer incidence in five continents, vol. VIII. IARC scientific publications No. 155. Lyon: IARC; 2002 .

[7] Parkin DM, Bray F, Ferlay J, Pisani P. Global cancer statistics, 2002. CA Cancer J Clin 2005;55:74-108.CrossRefMedline

[8] Ho JHC. Genetic and environmental factors in nasopharyngeal carcinoma. In: Nakahara W, Nishioka K, Hirayama T, Ito $Y$, editors. Recent advances in human tumor virology and immunology. Tokyo: University of Tokyo Press; 1971. p. 275-95 .

[9] Zong YS, Zhang RF, He SY, Qiu H. Histopathologic types and incidence of malignant nasopharyngeal tumors in Zhongshan County. Chin Med J (Engl) 1983;96:511-6. Medline

[10] Levine PH, Connelly RR. Epidemiology of nasopharyngeal carcinoma. In: Wittes RE, editor. Head and neck cancer. New York: John Wiley \& Sons; 1985. p. 13-34 .

[11] Shanmugaratnam K, Sobin LH. Histological typing of tumours of the upper respiratory tract and ear. 2nd ed. Berlin: Springer-Verlag; 1991 .

[12] Yu MC, Henderson BE. Nasopharyngeal cancer. In: Schottenfeld D, Fraumeni JF, Jr., editors. Cancer epidemiology and prevention. 2nd ed. New York: Oxford University Press; 1996. p. 603-18. 
[13] Vaughan TL, Shapiro JA, Burt RD, et al. Nasopharyngeal cancer in a low-risk population: defining risk factors by histological type. Cancer Epidemiol Biomarkers Prev 1996;5:58793. Abstract

[14] Hidayatalla A, Malik MO, El Hadi AE, et al. Studies on nasopharyngeal carcinoma in the Sudan I. Epidemiology and Aetiology. Eur J Cancer Clin Oncol. 1983;19:705-10. [PubMed[

[15] Abuidris DO, Elgaili EM, Elhaj AH, et al. Histopathological patterns of nasopharyngeal carcinoma in Sudan. Saudi Med J. 2008;29:962-5. [PubMed]

[16] Thompson LDR. Update on Nasopharyngeal Carcinoma. Head and Neck Pathol. 2007;1:81-86. [PMC free article] [PubMed[

[17] Wei WI, Sham JST. Nasopharyngeal carcinoma. Lancet. 2005;365:2041-2054. [PubMed[

[18] Chang ET, Adami HO. The enigmatic epidemiology of nasopharyngeal carcinoma. Cancer Epidemiol Biomarkers Prev. 2006;15(10):1765-1777. [PubMed [

[19] Yuan JM, Wang XL, Xiang, Gao YT, Ross RK, Yu MC. Preserved foods in relation to risk of nasopharyngeal carcinoma in Shanghai, China. Int J Cancer. 2000;85:358-363. [PubMed[

[20] Tabuchi K, Nakayama M, Nishimura B, Hayashi K, Hara A. Early detection of nasopharyngeal carcinoma. Int J Otolaryngol. 2011 Article ID 638058, 6 pages. [PMC free article] [PubMed]

[21] Abuidris DO, Elgaili EM, Elhaj AH, Elmustafa OM. Histopathological patterns of nasopharyngeal carcinoma in Sudan. 2008 Saudi Med J.; 29(7):962-5.

[22] Ameera A. M. Adam1, Nazik E. Abdullah2, Lamyaa A. M. El Hassan3, Elwaleed M. Elamin4, Muntaser E. Ibrahim1, Ahmed M. El Hassan1. Detection of Epstein-Barr Virus in Nasopharyngeal Carcinoma in Sudanese by in Situ Hybridization. Journal of Cancer Therapy, 2014, 5, 517-522

[23] Xie SH, Yu IT, Tse LA, Mang OW, Yue L. Sex difference in the incidence of nasopharyngeal carcinoma in Hong, 1983-2008: suggestion of a potential protective role of oestrogen.2013 Eur J Cancer ;49 (1):150-5

[24] Adham M, Kurniawan AN, Muhtadi AI, Roezin A, Hermani B, Gondhowiardjo S, Tan IB, Middeldorp JM . Nasopharyngeal carcinoma in Indonesia: epidemiology, incidence, signs, and symptoms at presentation. 2012 Chin J Cancer. 31(4):185-96.

[25] Chou J, Lin Y, Kim J, You L, Xu Z, He B, Jablons DM. Nasopharyngeal carcinoma-review of the molecular mechanisms of tumerogenesis. 2008 Head Neck.;30 (7):946-63.

[26] Vera-Sempere F, Burgos J, Botella MS, Morera C. Comparative analysis of Epstein-Barr virus $(E B V)$ detection by nested-PCR and non-isotopic in situ hybridization in nasopharyngeal carcinoma (NPC). 1998 Clin Chem Acta.; 23; 271(2):119-32.

[27] Hording U, Nielsen HW, Albeck H, Daugaard S. Nasopharyngeal carcinoma: histopathological types and association with Epstein-Barr Virus. 1993 Eur J Cancer B Oral Oncol.; 29 B(2):137-9. 